\title{
What if it switched on the sun? Exploring creativity in a brainstorming session with children through a Vygotskyan perspective
}

\author{
Marianne Kinnula, Tonja Molin-Juustila \\ INTERACT Research Unit, Faculty of Information Technology and Electrical \\ Engineering, University of Oulu, Finland \\ Iván Sánchez Milara, Marta Cortes, Jukka Riekki \\ Center for Ubiquitous Computing, Faculty of Information Technology and \\ Electrical Engineering, University of Oulu, Finland \\ (firstname.lastname@oulu.fi)
}

\begin{abstract}
We contribute in this study a first step in theory-based understanding on how creativity in collaborative design sessions relates to the elements that are present in a creative act. These elements include group composition, objects present, practices used, and previous knowledge of the participants. The context of this study was our search for lightweight methods for technology design with children, which can be used in a school context with large groups, will require as little amount of training as possible, and can be set up quickly. We formed a mixed group, consisting of young children, an older child and an adult, with the aim of involving children in creative collaborative brainstorming during the very early phases of design, so as to come up with fruitful ideas for technology development. We report our process and examine the implications of our results in relation to different elements that trigger and affect creativity in the collaborative design process. Use of Vygotsky's cycle of creativity as our theoretical lens together with timeline analysis method presented in the paper were essential for seeing beneath the surface of what happened in this complex, collaborative creative process. Our results can be used for further methodological development of creative collaborative sessions, both with children and adults.
\end{abstract}




\section{Introduction}

User involvement in Information and Communication Technology (ICT) development has a long tradition. Researchers in the Child-Computer Interaction (CCI) community, working with children in the ICT field, have embraced the approach as they wish to give children a voice in technology design. For over three decades, researchers have developed different methods and techniques for working in collaboration with children (Druin, 2002; Walsh et al., 2013). These cover all phases of design, from the early stages of development to evaluation and use. The methods followed during the early phases of design with children are often referred to as brainstorming techniques for new design ideas (Druin, 2002). It is quite typical, however, that the reported studies start with the situation where some kind of application or idea already exists before starting the collaborative sessions with children. Brainstorming has been referred to, for example, when eliciting 'likes,' 'dislikes,' and 'new ideas for improvement' from children as related to design solutions specific for the study (see, e.g., Norooz and Froehlich (2013) and Yip, Foss, et al. (2013)). Brainstorming with children for new ideas only, without any specific application, has not been the focus of previous research on CCI. Creativity in children's contributions, however, has been an issue of recent interest in the CCI community (Decortis et al., 2013; Thang et al., 2008). For instance, at the Interaction Design and Children Conference of 2013, there was a workshop on interactive technologies for enhancing children's creativity; i.e., encouraging them to explore their environment with fresh eyes, and enriching their expressive power and their abilities to think 'outside of the box' (Decortis et al., 2013).

We contribute to this discussion through an analysis of the creative collaborative process of brainstorming with children during the very early phases of design. In particular, we have looked at the methodological experience, aiming to get a preliminary theory-based understanding of how different elements that are present in a creative act relate to creativity during brainstorming for new technology in a mixed-age group. This is done with the help of Vygotsky's (2004) cycle of creativity as our theoretical lens. The context of our exploratory study is a brainstorming workshop that we arranged at a local school, in order to investigate children's vision on tangible interaction. Tangible interaction uses the material quality of physical objects to create interfaces with the digital world (Fitzmaurice et al., 1995; Ishii and Ullmer, 1997; Shaer and Hornecker, 2010). Our starting point was that the 'novelty' of the ideas or the 'appropriateness' of them might not be the best measures for the success of brainstorming sessions; therefore, we have not chosen to describe here novel concepts for tangible interaction, elicited from the brainstorming workshop, nor do we evaluate how creative the results of the workshop were as such. Instead, we examine how different elements in the brainstorming process relate to creativity, either hindering or triggering it in the 
participants, and then reflect upon these findings using Vygotsky's (2004) cycle of creativity.

As the basic setting of the workshop follows the best practices in CCI research, we contribute also by giving some possible preliminary theory-based explanations as to why these best practices seem to work well with children. We suggest that our results are relevant also when working with adult groups only. We also suggest a timeline analysis as a useful tool for reflecting and visualizing how different elements are related in a brainstorming session. We see our contribution as useful, especially when the intention is to develop brainstorming methodology further, as it can give possible explanations for why a given method works or what shortcomings it may have.

Moreover, topics related to children have recently started to appear in the ACM hosted Computer Supported Cooperative Work (CSCW) conference. So far, however, the European CSCW community has not shown much interest in collaborative work practices with children or in children as technology users, even though children are a significant and growing technology-user group and deserve to be heard when technologies are designed for their use. We therefore contribute also by bringing forward this interesting user group with which to collaborate.

School poses a somewhat challenging environment in which to work for a number of reasons, including lack of flexibility (Druin et al., 1999; Rode et al., 2003), traditional power structures in which a possible clash over collaborative work ideals between children and adults occurs (Druin et al., 1999; Iivari and Kinnula, 2016), and difficulties in fitting the technology design projects with curricula, the daily routines, and time constraints at the school (e.g., Iivari and Kinnula (2016)) Nevertheless, we still consider working with large groups of children in schools an important way to empower children and enable children's natural, genuine participation (cf. Hanna et al. (1997) and Iivari et al. (2015)) and to give them a democratic possibility for learning new skills in the design process (see also Iivari and Kinnula (2016)). However, in such a context it is useful to have lightweight, 'ad hoc' methods that require as little amount of extra time as possible on top of the design sessions (e.g., training of children) and are still meaningful and produce results, which can be used in future ICT development. Therefore, as a context of this study, we show in this paper one such way to collaborate with school children. We sought a method that required low partner experience, as little need for accommodation as possible, relatively low design space dimension, very early maturity of potential future design, and low dimensions for cost and technology. Portability and physical interaction were not considered (see FACIT PD framework in Walsh et al. (2013)).

In the next section, we describe the theoretical lens used in the study, Vygotsky's (2004) cycle of creativity, and give some background on brainstorming with children. After this, we introduce the research design. Then, we report our narrative account of the brainstorming workshop, treating it as a situated activity (Goodwin 
and Goodwin, 1996; Mondada, 2006), so as to make sense of the multimodal actions (Jewitt, 2009) of the participants and to reflect upon their relevance from the methodological point of view. In the final sections, we discuss our results in light of our theoretical lens, present the implications and limitations of our study and outline paths for future work.

\section{Related research}

\subsection{Vygotsky's cycle of creativity}

In our inductive analysis of the data for this study, we got interested in brainstorming as a creative process. Inspired by Decortis et al. (2013) who ponder how to help children to think laterally ('out-of-the-box'), we turned to Vygotsky's cycle of creativity (Vygotsky, 2004) as our theoretical lens as a means of providing possible explanations for what happened in our data.

According to Vygotsky, any human act that gives rise to something new is referred to as a creative act. The activity itself is a complex form of combining and reworking the impressions and elements of past experiences to generate something new. The complete 'cycle' of creativity means that all creativity originates from reality and ends in reality by altering it somehow (see Figure 1 for the cycle of creativity).

Vygotsky (2004) introduces four basic ways how creativity is associated with reality. First, all creations are based on elements taken from reality (a new combination, transformation, or distortion of those elements). Even the most farfetched creations are constructed from impressions originating from the real world. Creativity therefore depends on the richness and variety of previous experiences as material for creation. As Bratteteig (2004, p. 179) puts it, 'we design what we know'. Reworking the existing material is a complex process of dissociation (i.e., breaking up a complex whole into a set of individual parts) and association (i.e., unification of the dissociated and altered elements) (Vygotsky, 2004). So, to strengthen the basis for creative process, providing new experiences is a possibility. However, it needs to be kept in mind that 'too much' subject knowledge can curb the process, as it may result in looking at the problems as others have in the past (Sternberg, 2006).

The second type of association between creativity and reality is more complex. In this, the final product of creation corresponds to reality by virtue of other persons' experiences; i.e., instead of having a personal experience with something, a person's creativity is based on other persons' experiences (e.g., when reading news); thus, one is not limited by the boundaries of one's own experiences. Warr and O'Neill (2005) explain this as a social process combining 'the matrices of thought' in our mind and our environment. Third, creativity is associated with 
emotions. The creative results serve as expressions of internal feelings and have an effect on other people's feelings as well.

Fourth, the result of creativity as a construct of fantasy (in the internal reality, i.e., human thoughts, concepts and feelings) may represent something substantially new without any correspondence to any object of reality. Only after being externally embodied and shared (in material form, such as, for example, a drawing or a technical device) does it become an object of reality with the potential to originate creativity further (Vygotsky, 2004), as Schön (1992) discusses in relation to how the design process of seeing-drawing-seeing feeds itself. In the design studio context, Vyas et al. (2009) describe this as externalization of ideas in the forms of paper sketches, clay models or physical prototypes, to mention a few examples, maintaining that it supports collaboration, in a similar vein with that described by Sellen and Harper (2002) and Bratteteig et al. (2016). For Schön (1983, p. 175), design is 'a reflective conversation with the materials in the situation'. Vyas et al. (2009), furthermore, stress that in cooperative design 'material collaboration' is critical. It provides 'border resources for interaction' in the design process and helps in communicating ideas when words fail and (Jacucci and Wagner, 2007).

According to Vygotsky (2004), children's creativity is different from adults' due to their narrow experience-base and immature skills for reasoning. Even though children's skills on imagination increase during their childhood, Vygotsky argues that imagination grows independently of reasoning skills. Yet, reasoning skills affect the creations one is able to produce. Due to the independency between imagination (in Vygotsky's original work, imagination is seen as a basis of all creative activity; see Plucker et al. (2004, p. 9)) and reason, Vygotsky argues that children have poorer creative skills than adults (Vygotsky, 2004). On the other hand, society often suppresses the creative potential of adults by encouraging intellectual conformity (Sternberg, 2006). 


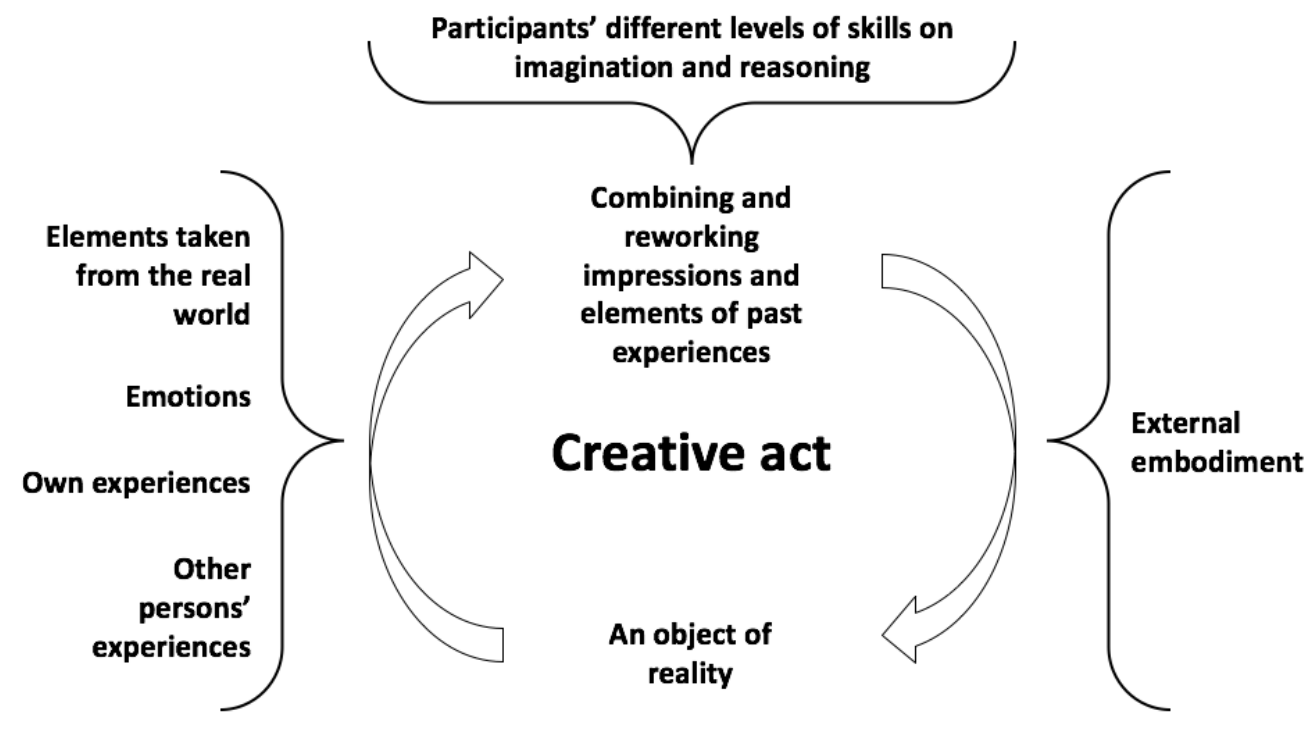

Figure 1. Elements in the cycle of creativity according to Vygotsky (2004).

In this paper, we define creativity based on Vygotsky as imagining, combining, altering and creating something new. Collective creativity, respectively, means the combined creativity of creative individuals (Plucker et al., 2004).

\subsection{Brainstorming with children for novel design ideas}

Children's contribution as users, testers, informants, or design partners during different phases of design has long been one of the core interest areas in the field of child-computer interaction research (Druin, 2002; Knudtzon et al., 2003). Empowerment of children and hearing their voices in design are central values in the CCI field (Yarosh et al., 2011) and have been called for in numerous research articles produced within the CCI community (e.g., Hourcade (2008), Iivari et al. (2015), Iversen and Smith (2012)). Especially within the tradition of the Cooperative Inquiry (CI) method (Druin, 1999), working in an intergenerational group where children and adults are equal stakeholders in the design process has been considered valuable, as children provide the expertise and knowledge of what 'being a kid' means and what kinds of things are interesting and useful for them. Adults, on the other hand, provide structure to the process. There are numerous studies where children and adults have worked together following different methods of brainstorming for the design of new solutions.

Practical guidelines for overcoming traditional power structures between children and adults have been developed for different phases of design, starting with brainstorming for a new design and ending with evaluation of a prototype or a product (Druin, 1999, 2002; Guha et al., 2013; Hanna et al., 1997; Pardo et al., 2005). In these settings, the goal for empowerment of children is built into the 
process through finding ways for showing that adults and children can work as equals on the same task. For example, adults are asked to elaborate ideas equally with children, wear informal clothing, and use first names (Druin, 2002; Guha et al., 2013). Le Dantec (2010), in a more general discussion of the creative process of design, highlights also the importance of the situated context; that is, how the distributed, enculturated and situated aspects of the process become manifested in a meeting. With 'enculturation,' he points to the fact that the process of design is not only situated in a particular time and place, but also in a cultural context that informs the kinds of problems and solutions that can be conceived through design (see also Bratteteig (2004, p. 162)). 'Several cultures mix together through the course of collaborative design' and they 'influence each other in a process of coevolution' (Le Dantec, 2010). All these, amongst other things, affect the interaction order between participants, i.e., why and how people interact in certain ways in different groupings (Goffman, 1981, 1983; Molin-Juustila et al., 2015), and that, in turn, affects ideas produced in design sessions with children (Kuure et al., 2010; Molin-Juustila et al., 2015) as well as with adults.

Specific methods used in design sessions with children have also been found to affect the results (Thang et al., 2008; Yip, Clegg, et al., 2013). Compared with prototyping, which typically results in relevant and workable solutions, brainstorming type of thinking seems to produce more divergent, surprising and novel solutions, which are useful for the early stages of design in particular (Thang et al., 2008). Recently, the collaborative elaboration of ideas within an intergenerational team has been highlighted as it contributes to creativity in the design process (Guha et al., 2013). In studies regarding adults only, involving mixed group of participants in brainstorming has been considered to be also a collaborative, social, creative process (Le Dantec, 2010; Warr and O'Neill, 2005), where group composition enables and enhances creativity by fostering the refinement of ideas during collaborative design activity (Warr and O'Neill, 2005).

With regard to young children, different types of objects have been used as triggers for exploration and imagination, and thus have inspired creativity (Wang et al., 2015) (cf. also Guha et al. (2013), about 'Bags of Stuff' in CI, for materials such as glue, clay, markers, etc., used for low-tech prototyping). Educating children with both design and subject knowledge (for example, definitions and concepts as well as practices, culture, and relationships within the context of use (Yip, Clegg, et al., 2013) has been considered for enhancing children's experience base, and thus enhancing their creative potential as well. It may result in imitation, which has also been seen as an important tool for creation (Kuure et al., 2010; Molin-Juustila et al., 2015).

As empowerment of children is one of the central goals of our research, we were inspired by Iivari et al.'s (2015) suggestion to use Chawla and Heft's (2002) framework for effective participation of children when planning and implementing projects. One of the aspects in that framework is that children are empowered by 
giving them real responsibility in the process. Therefore, we wanted to place a child as a session facilitator, as Yip, Foss, et al. (2013) also suggested studying children as leaders of design sessions further. According to them, children are capable of having a leading role in intergenerational collaborative sessions, if they are provided support in managing and directing the sessions and collaboration (Yip, Foss, et al., 2013).

\section{Research design}

\subsection{Overall setup}

The data for this study is part of a larger research project spanning over one semester, organized in Finland with one of our partner schools. The participating teachers considered our project to be an educating experience for the children, and so let us organize our research activities as part of their everyday schoolwork (cf. Garzotto (2008), Iivari and Kinnula (2016), Rode et al. (2003)). In spite of the challenges related to organizing research activities in a school environment, we deliberately chose to work with whole school classes instead of a smaller group of volunteer children at university premises, as we consider projects in school to provide the most natural way for genuine participation by children, as part of their everyday life (Iivari and Kinnula, 2016; Iivari et al., 2015). Typically, within this kind of setting, all children participate in the activities while only some of these children are studied for research purposes. The context for this paper was a workshop with a combined class of 46 children, consisting of 9 to 10 -year-olds ( $3^{\text {rd }}$ graders), with two teachers working as a pair. In this workshop, the children worked in groups with four different brainstorming tasks. The teachers allocated children into groups having the best knowledge of the working relationships among the children. One group of five of those children, working with one brainstorming task, was studied for this paper.

Inspired by the evolving practices in the CI tradition (Druin, 2002; Yip, Foss, et al., 2013), we wanted to pilot a setting where an older child facilitates a session planned for younger children, as we thought that, on the one hand, it might be easier and therefore also more empowering for the younger children to work when led by another child who is almost their equal, but just a little older than them, as compared to working on their own or led by an adult, and, on the other hand, we would be offering the older children an unusual experience in leading other children from an 'expert' position. We thus recruited school student union representatives $\left(5^{\text {th }}\right.$ graders, 11-12 years) to lead the brainstorming tasks. In addition, as the partnership between adults and children is an established collaboration form in this type of settings in the CCI field (e.g., Druin (2002)), the intergenerational elaboration of ideas have been considered especially useful (Guha et al., 2013), and we were also 
interested in exploring further the intergenerational aspect of collaboration, Master's degree students of Human-Computer Interaction were included as adult participants in the groups (see Table 1). The group analysed for this paper included five $3^{\text {rd }}$ graders ( 2 boys, 3 girls), a $5^{\text {th }}$ grader leading the group (a girl, 11 years of age, later on called 'the captain'), and a female university student (later on called 'the adult') (Table 1).

An informed consent was asked from all participants as well as the children's parents. All participants were free to end their participation at any time. Before the workshop, we organized two planning meetings with the $5^{\text {th }}$ graders. In addition, before (no data available on that) and after the workshop, we had some reflective discussion time among the $5^{\text {th }}$ graders that sought to prepare them mentally for the workshop and to relieve them from possible stress afterwards.

\begin{tabular}{ll} 
Participants & Role in the workshop (research team expectations) \\
\hline Researchers (4) & $\begin{array}{l}\text { Facilitating the workshop, assisting the captain when needed (focus: when there } \\
\text { seems to be some problems in the process) }\end{array}$ \\
\hline 3rd graders (5) & $\begin{array}{l}\text { Providing fresh ideas in a brainstorming session about what future technology could } \\
\text { be }\end{array}$ \\
\hline Captain & $\begin{array}{l}\text { Leading the brainstorming work in the group: facilitating and stimulating idea } \\
\text { generation, participating in the group work; had chosen this particular brainstorming } \\
\text { task by herself to lead }\end{array}$ \\
\hline Adult & $\begin{array}{l}\text { Equal participant in the brainstorming group work; knew only that the captain will } \\
\text { guide their work and the adult is not to take a facilitator role; had previously read } \\
\text { some scientific articles related to tangible interaction }\end{array}$ \\
\hline Teachers (2) & $\begin{array}{l}\text { Creating the group; present just in case of any incidence; no active participation in } \\
\text { the workshop }\end{array}$
\end{tabular}

Table 1. The participants' roles in the session

The workshop data (video and audio) analysed in this paper was structured in three phases: (i) introduction and orientation (14 min), (ii) transition phase (9 $\mathrm{min})$, and (iii) brainstorming session (27 min) (Figure 2). A reflective discussion (19 min) (only audio data available) with the $5^{\text {th }}$ graders followed about 30 minutes later.

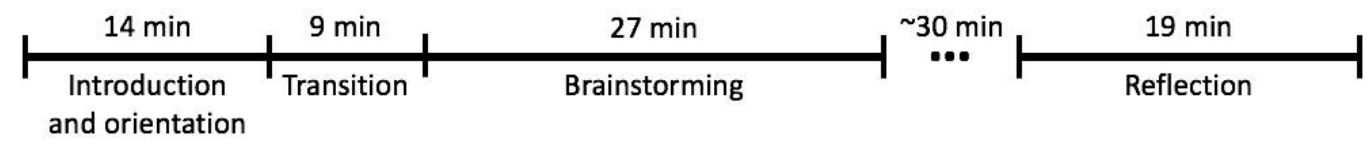

Figure 2. Timeline of the workshop

Wanting to stimulate the brainstorming process with materiality (Jacucci and Wagner, 2007), we placed a large number of small items on a side-table, to act as mediators for brainstorming. Different artefacts carry with them particular cultures and histories across time and space (e.g., Kuutti (1994)), which makes them useful, but also causes them to have a potentially restricting role (see e.g., Kuutti et al. 
(2002), Molin-Juustila et al. (2015)). Knowing this, we chose very diverse but quite familiar items, in order to support creativity of the participants related to the rather unfamiliar and abstract phenomenon of tangible interaction. These items were used for the orientation of the workshop participants (see more in section 4.1). The group and task studied in the current paper were chosen as a focus of our data analysis, given especially that the effect of material objects in the brainstorming process was very intriguing and different from any other workshop groups.

\subsection{Brainstorming session setup}

In the session table, there was a simple white board-like mock-up (Figure 3), empty papers (A4), markers of different colours, a sign with the captain's name on it, a list of names of the 3rd graders, and our audio recorder. The mock-up acted as a probe; it was aimed to bridge the physical and the digital world. The mock-up was to react somehow (decided by the participants) when in any type of relation with one or more materials (e.g., items). The material/type of interaction/response was subject to the participants' creativity. We used the mock-up in the brainstorming session to get new input for how to develop further a previously constructed padlike device that enables tangible interaction for active learning environments.

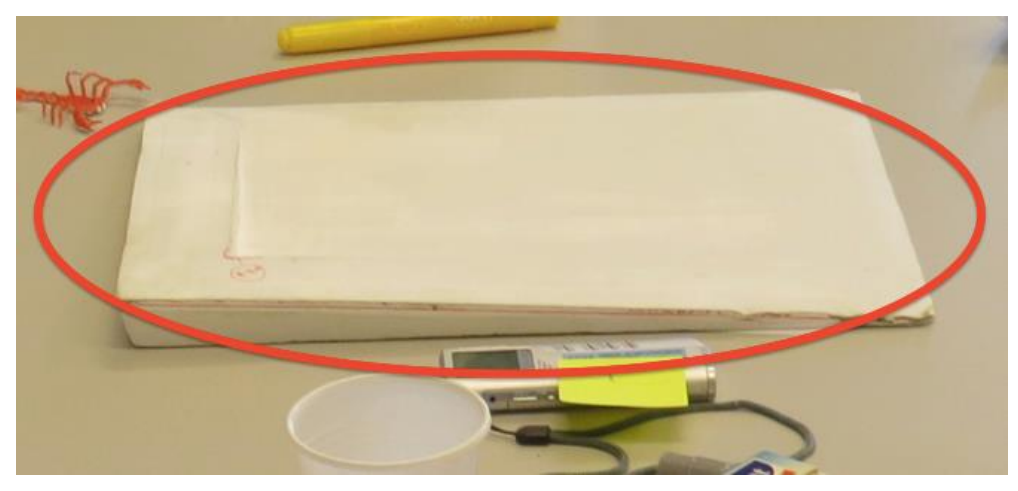

Figure 3. The mock-up on the table (about A4 size)

The brainstorming assignment was quite open, unfocused, and unspecified in order to increase the amount of new ideas produced, rather than dedicated to specific details or just a couple of highly developed ideas (cf. Yip, Clegg, et al. (2013) about more focused working). Based on the discussions in the planning meetings that we had had previously with the $5^{\text {th }}$ graders, we had prepared one page of guidelines to support the captain as a session facilitator. We tried to keep the guidelines as simple as possible to avoid confusion, yet have enough information to provide support. The guideline sheet was given to the captain a couple of minutes before the session. In the guidelines, she was asked to (1) initiate the task by asking the participants to brainstorm what would happen when one of the items on the table, or even several of them at the same time, were put on top of the mock-up. 
She was also asked to (2) encourage participants to consider what happens when moving the items on top of the mock-up (3) or when taking some (or even all) of them away. (4) Playing with the items and the mock-up was possible, or whatever the participants felt fun to do. It was also clarified that (5) the ideas were not required to be useful or (6) directly connected to the items they had on the table. (7) Anything they could imagine based on the materials available would be an interesting outcome.

There were also guidelines specific to the role of the captain. It was highlighted that (8) the participants should create their own ideas and that (9) the captain should try to encourage each participant to contribute (at least a little). Finally, (10) three suggestions were given on how to proceed if they ran out of ideas (e.g., picking up and elaborating each other's ideas). The captain was not explicitly instructed whether she should participate in the idea generation or not (e.g., by creating new ideas by herself), but she was asked not to monopolize the discussion. The captain was not expected to take notes nor asked to organize new ideas in any way, to avoid the potential challenges she might have otherwise faced (Yip, Foss, et al., 2013).

We followed the tradition of video analysis practices (Knoblauch et al., 2008; Mondada, 2006). Data used in the current study included video and audio of the workshop (including the reflection session after the workshop) and a field diary of the adult university student. When analysing the data, two of the authors reviewed both the video and the audio recordings of the workshop, first individually to make a shared transcription of the session, and then together, extracting one by one the ideas generated during the session. Later, the authors reviewed the videos together to take notes about other interesting aspects (e.g., interactions, gestures, facial expressions, activities going on around the table). The reflection session was also reviewed. We coded the ideas from the video using the following criteria: the 'originator' of the idea (the captain, the adult, one of the children), the materials (paper, the mock-up, a (personal) item), type of interaction (moving, squeezing, throwing, etc.), and how realistic the idea is (whether the idea could be used to build a future prototype or not). The field diary of the adult as well as separate discussions with her were also used to check some of our interpretations. All the authors reviewed the analysed material so to agree on the main findings. Then, we created a timeline diagram (Figure 7) in order to visualize occurrences of the different events along time and to try to infer cause-effect relations. Finally, we reflected our findings against Vygotsky's cycle of creativity to get some preliminary theory-based explanations for our results.

\section{Flow of the workshop}

Next, we report our analysis of what happened in the workshop. In our inductive analysis of the data, we were able to see certain events/clusters of events that seemed to characterize the working and affect the results. Those are discussed in 
the following sub-sections, with a detailed description of what happened. The intent is to create for the reader an immersion in the events, which contributes to a deeper understanding of our findings. After this, we show a visualization of the brainstorming session in the form of a timeline, showing the relationships between events, ideas, and materials.

\subsection{Introduction and orientation}

Opening. All 46 of the $3^{\text {rd }}$ graders, their two teachers, and the university students are sitting in a classroom, around tables, and we, the four researchers, and all of the $5^{\text {th }}$ graders are sitting/standing in front of them. One of the researchers opens the workshop and describes the purpose and the structure of the workshop as well as the role of each captain as a leader for the session and an adult university student as an equal session participant. The researcher emphasizes that there are no good or bad answers; everything one can think is valid.

Broadening of experiences. Next, we try to induce the participants into a fertile state of mind to brainstorm for new technologies for tangible interaction. According to Vygotsky's cycle of creativity (Vygotsky, 2004), we are broadening our participants' experiences. We first explain the concept of tangible interaction and how the digital and material worlds can be connected using familiar examples: a Wii video game console and a YouTube video about Makey Makey (an invention kit that allows one to 'turn everyday objects into touchpads').

Then, each researcher chooses one item from the side table and describes what kind of ideas and possibilities for tangible interaction that item brings to their mind. After that, five $5^{\text {th }}$ graders do the same (Table 2). We had previously discussed with the $5^{\text {th }}$ graders what kind of ideas we all could present during this orientation and agreed that they did not need to present anything if they did not want to. The captain chose not to present any item/idea.

\begin{tabular}{lll} 
Participant & Item & Related idea \\
\hline Researcher 1 & A coffee mug & $\begin{array}{l}\text { 'When I swung this empty coffee mug, the [coffee] machine in } \\
\text { the teacher's lounge would turn on.' }\end{array}$ \\
\hline Researcher 2 & Little toy dog & $\begin{array}{l}\text { 'I take this with me to my office and while I am scratching this } \\
\text { toy a machine at my home scratches my dog there.' }\end{array}$ \\
\hline Researcher 3 & Packet of tissues & $\begin{array}{l}\text { 'When I'm watching a film at home... When I take this [packet of } \\
\text { tissues] the lights will turn blue and soft [to match the mood of } \\
\text { the film].' }\end{array}$ \\
\hline Researcher 4 & A DVD case & $\begin{array}{l}\text { 'When I put a DVD case close to TV, the film automatically } \\
\text { starts. To hear the soundtrack [of the film] I go to the stereo } \\
\text { system.' }\end{array}$ \\
\hline $5^{\text {th }}$ grader 1 & A school book & $\begin{array}{l}\text { 'If a school book got lost you could call with your phone to the } \\
\text { book and it would start ringing.' }\end{array}$ \\
\hline $5^{\text {th }}$ grader 2 & A toy train & $\begin{array}{l}\text { 'If one had a small train... It could be placed on a pad [similar as } \\
\text { was used in the brainstorming session in this paper] and you } \\
\text { would hear some information about that item then.' }\end{array}$
\end{tabular}




\begin{tabular}{lll}
$5^{\text {th }}$ grader 3 & A crocodile figure & $\begin{array}{l}\text { 'If you had a miniature crocodile you could take care and feed } \\
\text { the actual living crocodile by using that miniature item.' }\end{array}$ \\
\hline $5^{\text {th }}$ grader 4 & A ghost figure & $\begin{array}{l}\text { 'If I had a 'ghost' in my hand, and I squeezed it, then a movie or } \\
\text { some text would appear on the wall.' }\end{array}$ \\
\hline $5^{\text {th }}$ grader 5 & A bear figure & $\begin{array}{l}\text { 'If I had lost my teddy bear and I squeezed this, the teddy bear } \\
\text { would give me some voice signal and I'd be able to find it.' }\end{array}$
\end{tabular}

Table 2. Example items and related ideas

Choosing the items. Next, we ask the workshop participants to choose one item from the table and suggest that participants could introduce their own items to each other and discuss those in their own groups. The brainstorming session participants studied in the current paper choose the following items: a male figure playing saxophone (the adult), a bear figure (Girl 2), and a scorpion figure (Girl 3), a baby bottle (Girl 1), a packet of band aids (Boy 1), and a packet of cake candles (Boy 2) (Figure 4).
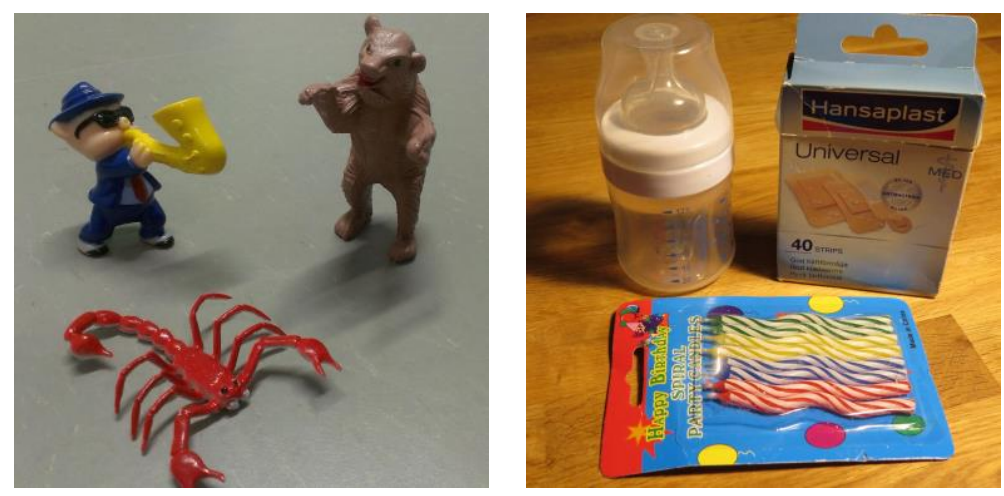

Figure 4. Items chosen by the brainstorming session participants

\subsection{The transition phase}

Now different groups scatter into their session tables and have some juice and cookies (similar to 'snack time' in CI, in Druin (2002)).

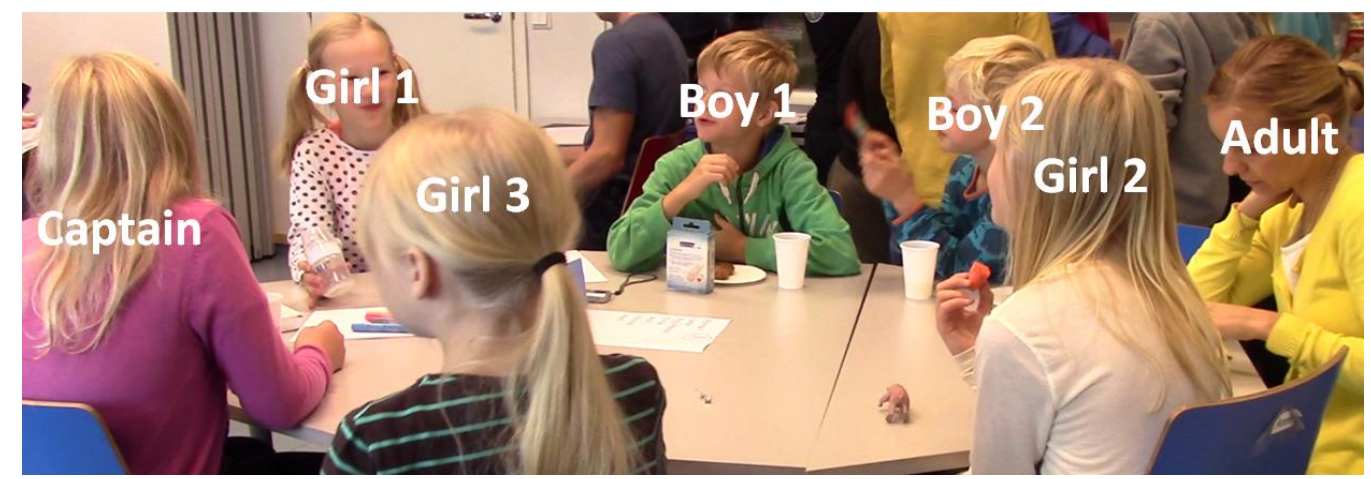

Figure 5. The participants of the brainstorming session 
Confusion. During the transition phase, there is confusion within the group we study for this paper with regard as to what to do next. Participants (Figure 5) are enjoying the snack, but at the same time are expecting clearly for something to happen. Two boys introduce their own items: Boy 2, having a packet of candles, says that 'the candles will ignite just by themselves'. Boy 1, with a packet of band aids, explains how 'a band aid will automatically cover the cut when the package is opened'. Girl 1 asks Girl 2 about her bear, but no meaningful discussion comes out of that.

Starting the work is challenging for the captain. Particularly interesting in the transition phase is that the captain is also obviously confused about her role. She reads her guidelines several times, holding them in her hand, then places them back on the table, glancing around the room, as if waiting for something. A couple of times a researcher comes to her to ask if she has any questions ('no') and gives her some general advice. After one of these visits, the captain moves the mock-up from the edge of the table to the centre of the table and starts reading her guidelines again. It seems that starting the work is challenging for her. She does not interact with her group, but seems to wait instead to start the session. There were no specific guidelines for the captain on how to start working or what to do during this transition phase or with regard to the introduction of the items, and we assume that it may be the reason why she does not take the leading role in the situation. Finally, the researcher informs: 'Let's start the group work now' (this is shown as event 'R: Start session' in Figure 7 in section 4.5).

\subsection{The brainstorming session}

The session starts slowly. Girl 1 takes a leading move by asking Girl 3 what is her idea with the scorpion, continuing the introduction discussion of the items. After Girl 3 finishes her talk, the captain tries to take a leading role by asking Girl 2 what she would innovate with her item (a bear figure) and if it could be somehow connected to the mock-up, by pointing to the mock-up while presenting the question ('C: Points mock-up'). Then Girl 2 introduces her idea with the bear figure without any connection to the mock-up. At this point the captain obviously tries to change the focus of the brainstorming more towards the mock-up. Participants present some ideas; the adult's idea is related to the mock-up. The captain keeps reading her guidelines as if she knew that the process is not going as it should. Then, the researcher passes by, bends down towards the captain only, and very briefly comments to her that they may start now if they are ready ('R: Checks on captain').

The captain takes a leading move. Now, the captain quickly reads her guidelines again and then starts to talk to the participants for quite a long time, explaining what they are supposed to do ('C: Explains mock-up'). She takes the scorpion and taps it against the mock-up while explaining that the participants are 
expected to envision what would happen if items were put on top of the mock-up, e.g., 'if one liked to have this animal as a pet, by placing it here it would go to one's shopping list'. The adult tries to clarify whether the mock-up should be used with one's own item only by lifting her item in the air, and the captain nods. At this point, interaction between the adult and the captain fails. Now, participants seem to think that all ideas should be related to one's own item, which is in conflict with the captain's guidelines (ideas were not required to be directly connected to the items). However, right after that, Girl 1 places her baby bottle on top of the mockup and starts wondering if it would somehow change, but she falls short of how to continue the idea and gains no support from the others. For almost two minutes, nothing productive happens. Based on the body language and gaze movement, one would say that the captain is expecting contribution from the participants. Perhaps the adult feels responsibility since, after a while, she comments 'I need to think more'. Right after that, Girl 2 places her bear on top of the mock-up, suggesting that when the bear moves there it will start recording something.

The adult gives cues with her own behaviour. After this (about $8 \mathrm{~min}$ from the start), the adult - looking somewhat confused - asks the captain to read the guidelines aloud so that all can hear them ('A: Asks instructions'). At this point, Boy 2 needs to go to the rest room and he is therefore not present to listen to the captain's instructions. The captain tries to read the instructions aloud (' $\mathrm{C}$ : Instructions'). However, the guideline text has been formulated only for her own use. So, instead of reading them word for word she reads and simultaneously tries to turn them into instructions for the group (seemingly challenging for the captain). After the captain's instructions (she reads only the first three of them) the adult is ready to continue and places her item on top of the mock-up and explains her idea. Boy 1 continues in a similar way with his own item. Boy 2 returns to the table, while Girl 1 explains her idea using her item and the mock-up. Unfortunately, however, next Boy 2 provides his idea without any connection with the mock-up. At this point, the captain suggests a new practice: the participants could continue from each other's ideas. But the productive phase was broken again. Nobody seems to be willing to start.

External help. Aware of the situation, the researcher interrupts by suggesting that they could also use several items at the same time and, for example, create a game by placing the items on the mock-up in a specific order. At this point, the adult also gets a clarification from the researcher whether they should always use their own items or not ('CH \& A: Ask instructions'). Until this, all the ideas have been connected to one's own items. The researcher tries to open the minds of the participants by taking a marker from the table, placing it on the mock-up and suggesting that the marker could represent a tree and when placed on the mock-up it would show information about the species ('C \& R: Instructions').

The group is self-guided. After the researcher leaves, Girl 2 presents her new idea, related to a birthday theme, and this way continues the idea of Boy 2 and his 
candles, yet without any connection to the mock-up. The captain is organizing the markers on top of the mock-up, perhaps as a sign to make the group focus more on it. Girl 1 asks from the adult whether they should now follow the practice suggested by the captain earlier and they agree, i.e., they continue from each other's ideas (' $\mathrm{CH} \& \mathrm{~A}$ : Agree to follow instructions'). The participants are now leading themselves. After a short break again, the adult seems to feel responsibility to start by continuing with the birthday-candles theme. None of the ideas presented next are connected with the mock-up. The participants follow the unstated counterclockwise order again. At some point, the captain touches the markers on top of the mock-up. This is a very nice subtle gesture to remind participants about the mock-up, yet without any results. After presenting her idea, it seems that Girl 1 is expecting the captain (sitting next to her) to continue but the captain does not do that. Instead, the captain turns to Girl 2 on her right side as a sign for her to continue next. However, Girl 2 is not ready to continue and therefore, brainstorming breaks down. Now, the participants seem to be stuck with the process of continuing from each other's ideas, instead of just having the creative possibility to continue if they want. The captain is probably not able to see this and therefore she is not able to support the participants. As the captain is not contributing herself, she is no role model for the others either.

Use of paper and markers releases creativity. The researcher, noticing the breakdown, approaches again, touches the white papers, and suggests using pen and paper as a black canvas: participants could draw (or write) something and devise the mock-up's response after placing the paper on it ('R: Use drawings'). The researcher explained this to the captain before starting the session but the captain was unable to connect the papers and markers with the session, possibly because they were not mentioned in her guidelines. Girl 1 takes the lead by taking a marker and starting to draw on a paper. Other girls take markers and papers too. Two ideas related to drawings, but not to the mock-up, are presented. Then the adult, not having a paper to draw on, presents an idea by combining the scorpion (not her own item this time) and the mock-up. This could be considered as a sign from the adult to focus more on the mock-up. Purposeful or not, after this the $3^{\text {rd }}$ graders start to create ideas by connecting their drawings with the mock-up. Interestingly, also the captain gets carried away with one of the ideas by continuing from there and making it more realistic compared to the original idea. This is the only time she contributes as a participant during the whole session. At this point of the session, the $3^{\text {rd }}$ graders are very productive. It seems that the possibility to draw things to be placed on the mock-up inspires them. All the $3^{\text {rd }}$ graders are drawing, yet, the captain and the adult are not. The unstated order also breaks now, as the children contribute whenever their drawings are ready. Even Boy 2, having no previous idea connected with the mock-up, is now finally able to connect his picture of a birthday cake with the mock-up. However, he still seems to be stuck with his original item, the birthday cake candles. 
The participants get tired. After 7 minutes of intensive brainstorming with drawings, the session has taken a bit over 20 minutes in total and it is clear that the participants are getting tired. The children are swinging their chairs and writhing restlessly. Then, the researcher interrupts again by suggesting that the participants could also combine their ideas and continue from each other's ideas ('R: Continue idea' in Figure 7). Girl 1 takes a leading role again and suggests that she might start and the others could follow from her idea. However, she struggles with creativity and finally creates an idea related to the mock-up and a plastic cup located on the table. Then, the others try to continue by using the cups and the mock-up as well (Figure 6). However, time is out and the session ends.

\subsection{Reflective discussion}

The captain remains quiet. After the actual workshop ended, one of the researchers discusses with all the $5^{\text {th }}$ graders their experiences as session leaders: was it fun, did they feel uncomfortable during the session, what went wrong. While some of the $5^{\text {th }}$ graders are very vocal about the problems in their sessions, our captain does not say a word. When the researcher asks the $5^{\text {th }}$ graders to tell whether they would do something differently, each of them answers that they have no immediate ideas of how to change anything. This is the only time our captain says anything during the reflection discussion: 'I can't think of anything'. This shows clearly her quiet nature, which we had observed already in the planning meetings.

\subsection{Ideas produced in the session}

When observing the session in situ, there were clear difficulties to get the creativity flowing in the group. However, when analysing the data by looking specifically for single ideas, we were surprised with the number of ideas the participants came up with: the adult produced 7 ideas, the younger children 31 ideas, and the captain one idea, altogether 39 ideas plus the captain's first example of mock-up use. However, the purpose of this session was to brainstorm specifically in relation to the mockup, to have children's view on the interaction with this artefact, and only 23 of the ideas were related to the mock-up. There are rather accidental reasons for that: in the beginning of the session, children presented their ideas before knowing that they should be using the mock-up but the adult had grasped the idea probably from the orientation; Boy 2 did not hear the instructions of the captain as he was in the restroom at that time and therefore did not know what he was supposed to do, later he was also writhing and moving around a lot, not concentrating on the task; and, some of the ideas just were separate, for no apparent reason.

The items chosen in the transition phase definitely influenced the session, just as we had anticipated, but we were not prepared for how heavily: 20 of the 37 ideas were related directly to the items (e.g., the birthday cake candles: 'if you placed these candles on a cake then they would show the lights of different colour' or 'if 
candles ignited, then you could hear happy birthday song from the background'), and three more ideas had elements inherited from the items (e.g., 'if you would like to have a cake for a birthday party and Mom were too tired to make one, then you just draw a cake (...) and place the drawing on the device and it will 'create' a real cake on top of the paper'). There were also four ideas related to plastic cups from which participants were drinking juice (Figure 6).

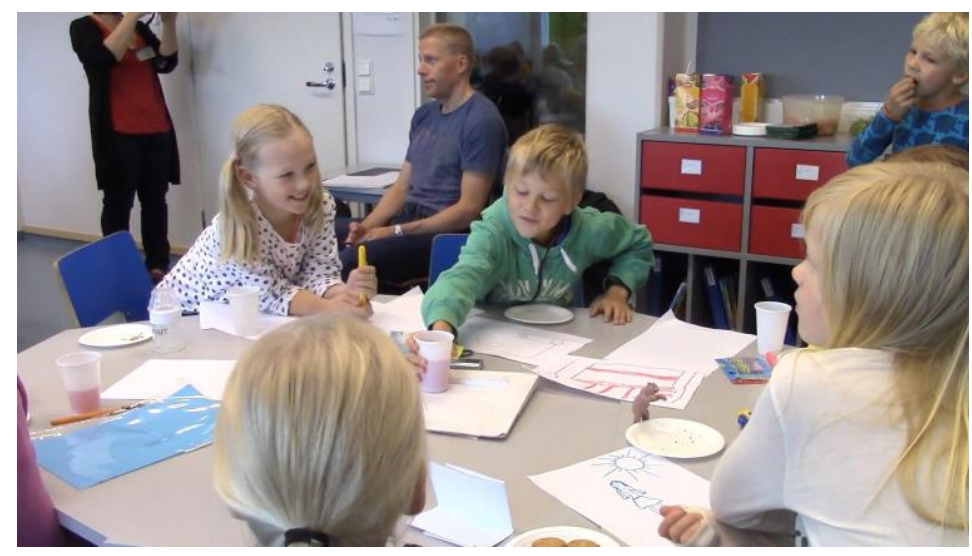

Figure 6. Children presenting a new design idea by connecting a plastic mug with the mockup

There are no clear connections in the ideas to the examples presented in the orientation phase. Some of the ideas resemble one of the ideas presented in the orientation phase (setting a toy train on a pad) but a similar kind of example was presented also by the captain when she was explaining the mock-up.

To visualize connections between ideas, important events and core materials, we created a timeline of the 27 min brainstorming session (Figure 7). Relevant events along the timeline of the session are presented as vertical lines (black or white 'pins') with explanatory labels. From our analysis perspective, relevant events are the actions directly produced by the facilitators (researchers/the captain) or participants (children and the adult) that modify the flow of actions or trigger a remarkable reaction in the participants. Events like 'the researcher giving instructions to the group' or 'children asking for instructions' fall into this category. Events produced by the facilitators are marked as black pins while events started by participants are marked with white pins. Text in the labels describes the event and indicates who produces it (C: the captain; R: the researcher; $\mathrm{A}$ : the adult; $\mathrm{CH}$ : a child). The four horizontal lines (composed of various coloured symbols and labelled as: 'All ideas,' 'Item related,' 'Mock-up related,' 'Paper related') show how the ideas produced during the session are connected with the core materials, that is, when participants utilized either the items, the mock-up, or a sheet of paper in the idea elaboration. The top row shows all the ideas produced during the session. The second row shows the ideas connected to the items the participants 
chose at the beginning. The third and fourth rows show how the ideas are related to the mock-up and paper.

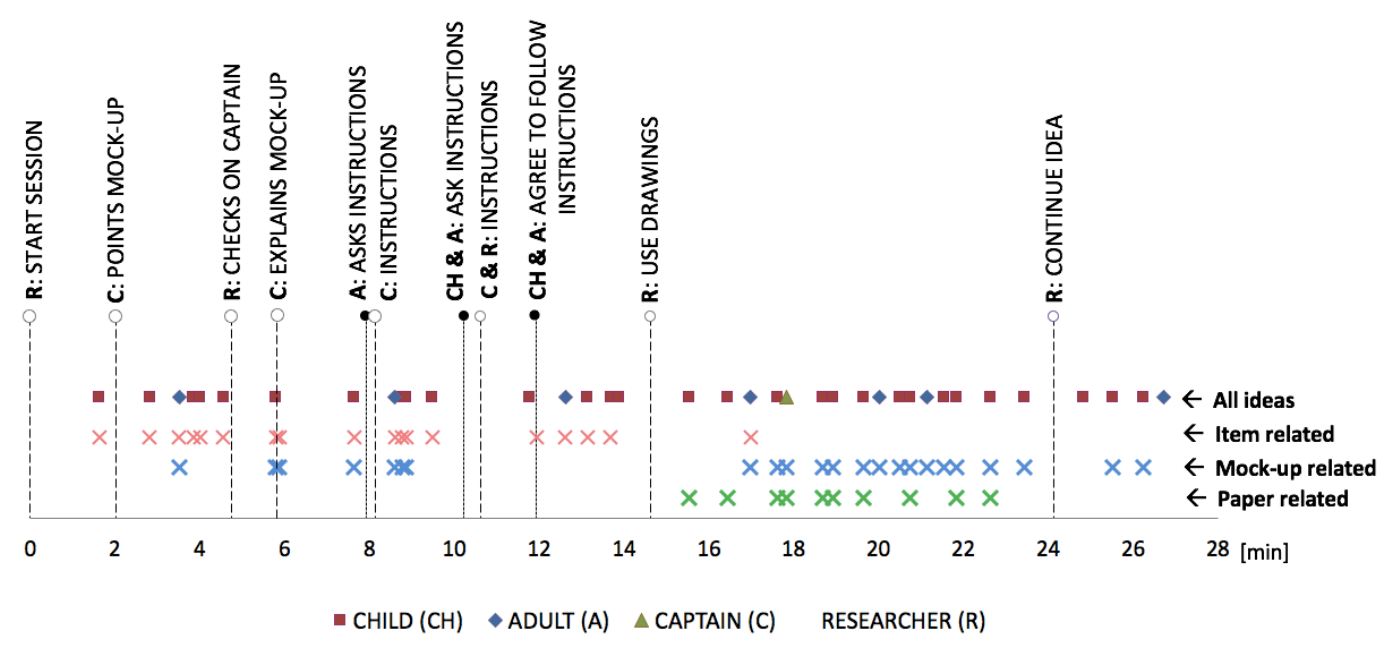

Figure 7. Timeline of the brainstorming session, visualizing connections between ideas, important events, and core materials

The timeline visualization allows us to understand how the different facilitation events had an effect in the process. We can see from the second row in Figure 7 how, at the beginning of the session, most of the ideas were related to the items the participants selected. The mock-up was also used from the beginning of the session (row 3 in Figure 7). In the beginning the ideas utilizing the mock-up were generated by the adult ( 2 of 6 ideas) with all the 5 children generating 4 of the 6 mock-up related ideas. This situation changes after the researcher approaches the table and invites the participants to use the paper and the markers (R: Use drawings). Before that event, the number of ideas utilizing the mock-up was just $7 / 17$ (41\% of the ideas produced so far). After the event, children started to include the mock-up more often into their ideas (16/22 -> 73\% of the ideas presented after the event used the mock-up). The mock-up thus became the centre of inspiration, moving the items to a second plane. There was still, however, an indirect relation to the items in some of the ideas; e.g., to the birthday-cake candles: 'You could just draw to that what you wanted to be served in the birthday party'.

Type of ideas. When looking for ideas that more generally relate with tangible interaction in a realistic manner, we found out that 12 of the ideas can be utilized in our future research. Six of these ideas were presented by children, 5 of them related to their own items and 1 related to paper; 3 ideas were presented by the adult, 2 of them related to her own item and 1 related to Girl 3's item; and 3 ideas resulted from group elaboration. The ideas provide either a viewpoint for how to develop technology further or directions for how to develop tangible interaction, either as concepts that can be further explored or guidelines on how to implement the interaction itself. We established the following criteria to define 'a reasonable 
idea for tangible interaction' for the analysis: there should be interaction, the action must be started by someone, and no 'magic' should be involved. One example of a discarded idea would be 'the candles will ignite just by themselves,' which does not fulfil any of the above criteria.

Facilitators. Although the researchers tried to avoid participating in the process, it is clear from Figure 7, that they had an instrumental role comparable to the captain: 3 key events were performed by the researchers after the start of the session, 3 by the captain and 1 joint action between them. Three more events were performed by the adult. With respect to the role of the captain, she clearly took a facilitator role. She was not asked to avoid generating new ideas but she refrained from sharing her own ideas with the participants. In total, the captain produced one idea plus her example when explaining the mock-up use. This led us to hypothesize that the captain had managed to interiorize the role of a facilitator and presumably did not see producing idea as part of that role; we did not ask her in the guidelines explicitly to produce (or not to produce) new ideas, but she proposed her only new idea with the intention of fostering idea generation among the rest of the group, we think. The adult both helped in structuring the session and also by presenting ideas. Three of her altogether 7 ideas were independent of the children's ideas, and 4 of them were somehow related to what children had presented. Of those 4 , in one she continued a child's idea as they had agreed to do so; in one she continued the juice mug ideas presented by children, but with an independent idea of her own; and in two ideas, she developed children's 'magical' ideas further along a more realistic direction.

\section{Discussion}

The aim of this paper was to get preliminary theory-based understanding of how different elements present in a creative act relate to creativity when brainstorming for new technology in a mixed-age group. As a context for this study, we tried out a lightweight brainstorming method with children in a school context. We created a group with children of different ages, together with an adult (Druin, 2002), and gave an older child a facilitator role (Yip, Foss, et al., 2013). This last detail was inspired by livari et al.'s (2015) call for empowering children by giving them more responsibility in design sessions. We provided the participants with tangible objects and a mockup of a technological device as materials to scaffold and stimulate their creative process. As a result of the session we were looking for genuine, creative ideas that are still reasonable; i.e., ideas that are at least to some extent implementable with existing ICT potential, to be used in further development of our prototype.

In Figure 8 we combine both Vygotsky's (2004) creativity cycle as well as experiences from our own data and previous literature of working with children. The elements in Figure 8 originating from Vygotsky are presented in bold font (cf. 
Figure 1). The rest of the elements in Figure 8 originate from our data, backed up with findings in previous literature.

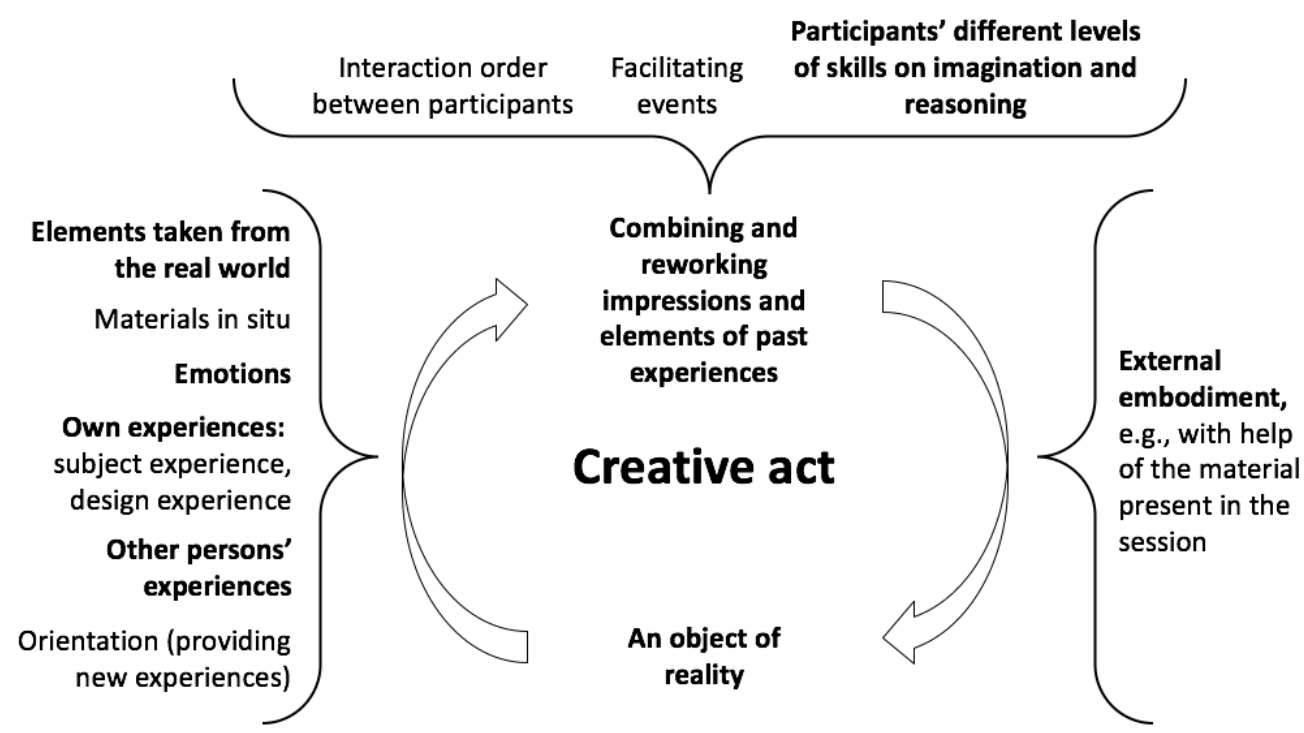

Figure 8. Vygotsky's cycle of creativity complemented with our data and literature on brainstorming with children (cf. Figure 1)

Next, in sections 5.1-5.3 we discuss our results related to the elements present in a creative act, shown in Figure 8, and the implications to arranging similar types of sessions. Then, we continue with discussing timeline analysis as a useful tool for analysing complex collaborative situations, as well as our experiences of the lightweight method we tried out in the school context.

\subsection{Materials in situ and external embodiment give form for thoughts}

According to Vygotsky (2004), only after one's own internal reality (thoughts and ideas) becomes externally embodied as an object of reality can it become the basis for further creativity, a new experience. We see that this showed in two ways in our data.

First, our idea to stimulate the brainstorming process with materiality (Jacucci and Wagner, 2007) by letting the participants select their items in the end of the orientation session gave the participants existing objects of reality, elements of the real world, to help them to start creating new ideas and to transform those to new experiences. That turned out to be both enabling as well as limiting to the participants' creativity. On the one hand, the items used to initiate the brainstorming on tangible interaction clearly increased the creativity, but they also limited participants' imagination through encouraging the tendency to stick with ideas related to particularly 'one's own item' or the items of other group members 
(cf. Kuure et al. (2010) about how examples provided by facilitators showed in many forms in children's creations).

The birthday theme was very prominent in the session, due to Boy 2 sticking to his cake candles; every single idea of his was somehow connected to a birthday theme and others were drawn to follow this theme. His only idea related to the mock-up was a drawing of a birthday cake that transforms into a real cake when you put the drawing on the mock-up. We can see here both the great positive force of recycling of ideas, in the form of reworking experiences (cf. Vygotsky (2004) and Figure 8, also Kuure et al. (2010) about imitation and recycling of ideas) but also the negative side of it when getting stuck with the same theme (cf. Kuure et al. (2010) about very similar productions of children). Even for the adult it was hard to step over the boundaries of the items. We were not surprised to see the restricting role of the artefacts (see e.g. Kuutti et al. (2002) about role of artefacts) as such but the extent of that came as a surprise to us. Notable is, however, that the related ideas fluctuated in the collaborative brainstorming process and grew farther from the items; e.g., starting from the cake candles and ending with birthday gift ideas - a good example, once again, of combining and reworking experiences. On the other hand, ideas related to the plastic mugs point to the possibility of any in situ material objects triggering one's creativity. Perhaps the problem with the items was that the participants 'owned' their items instead of bringing them for shared use? We suggest careful consideration of what kind of material objects are used for triggering creativity, and also consideration of how the ideas and thoughts of participants are wanted to be triggered: birthday-themed objects may lead to ideas related to festivities, as in our case, and healthcare themed objects may lead to ideas related to sickness and health.

Second, an interesting finding was how materials in situ helped in external embodiment of ideas, such as the use of pen and paper together with other material triggered a large number of ideas in children in a rather short time frame. We see this as the externalization of ideas that Vyas et al. (2009) talk about, and maybe it was also related to 'seeing-drawing-seeing' that Schön (Schön, 1992) discusses in relation to the design process? We believe that in this brainstorming session, empty paper gave the children a familiar tool to materialize their inner thoughts (cf. (Vygotsky, 2004) about external embodiment), communicating the ideas when words failed (Jacucci and Wagner, 2007); and indeed, drawing is widely exploited when working with children (see e.g., Large et al. (2007) and Literat (2013)). The 'Bags of Stuff' in CI (Guha et al., 2013) are also meant for externalization of the ideas, by providing different material to work with. The adult did not use paper at all, however. This might point to the differences of skills between children and adults. Adults may find it easier than children to express their abstract thoughts with spoken words while children might find it easier to express their imagination with the support of drawings. The adult also told us afterwards that she is not very used to drawing. We suggest stressing use of pen and paper in brainstorming, 
particularly with children, but also with adults, and also continuing each other's ideas, e.g., by adding something to a drawing started by another participant, or reworking parts of an idea to a new form some other way.

\subsection{Different levels of skills and interaction order}

According to Vygotsky (2004), children's reasoning skills develop independently of their imagination skills; therefore, adults and children are on different levels regarding their creative skills and this affects what kind of creations they are able to produce. Vygotsky (2004) also claims that creativity may be triggered by other person's experiences. In other words, an idea coming from one participant might become the basis on which the other participants generate new ideas. Moreover, it has been claimed that the creative potential of adults has been suppressed by a society that encourages intellectual conformity (Sternberg, 2006). This provides interesting possibilities for design with regard to group composition. In CCI, field intergenerational collaboration is a common practice, especially in the CI tradition (Druin, 1999; Guha et al., 2013), and collaborative elaboration of ideas, specifically transforming of 'fantastic' or 'magical' ideas to more realistic ones, has been reported to contribute to creativity (Guha et al., 2013).

In our data, several children presented very unrealistic ideas. Then the adult, seeing the potential of the idea, developed it further by taking it in a more realistic direction, thanks to her more developed reasoning skills. Thus, children's fantasies were also triggers and fuel for the adult's ideas, just as Vygotsky explains. A great example of that is the moment when Girl 2 imagined a device that can make the sun shine suggesting: 'Here is the sun' (drawn on paper). 'If you placed this sun on top of the mock-up and it is a rainy day, the sun would start shine'. However, the adult continues the idea, making it more reasonable: 'It could, instead, switch on the lights in the room'. Similarly, Girl 1 said: 'if you put a (drawing of a) flower on the mock-up it will create a lot of them, to form a bouquet'. The adult makes this idea more reasonable again and suggests 'what if, when you put the flower (on the mock-up), it showed you information about that flower?' This demonstrates how elegantly both parties in this group use their skills, situated at different levels, when contributing to the development of an idea. The child, who has imaginative skills already sees technology as magical, making all kinds of things possible, while the adult, grasping the essence of the idea and using her more developed reasoning skills, is able to develop it further (cf. Guha et al. (2013) about critical discussions in the end of a brainstorming session). This points to the potential of mixed-aged groups in general, or at least the power of collaborative elaboration as Guha et al. (2013) report. Externalization of ideas (Vyas et al., 2009), discussed in the previous section, clearly supported collaboration in our data (Bratteteig et al., 2016; Sellen and Harper, 2002) quite similarly as described by Bratteteig et al. (2016), who examine how design ideas evolve in a collaborative process. This is also in line 
with Warr and O'Neill (2005) regarding group composition enhancing creativity by fostering the refinement of ideas, and with the concept of collective creativity (Vygotsky, 2004). We suggest that the strengths of different ages when working in groups also could be utilized more consciously in the design process when developing technologies more widely, not only for children's use. Children might come up with a large number of unusual ideas (cf. Druin (1999) and Scaife and Rogers (1999) about children's creative capacity) and adults or older children could help to filter and develop the ideas further, transforming them into more realistic ones. However, in order for this to succeed, interaction order between the participants needs to be negotiated deliberately (Iivari et al., 2015) and power relations taken into account and relaxed (Druin, 2002).

Effect of the situated context (Le Dantec, 2010) showed in our data in relation to elaboration of the ideas, as the brainstorming session participants mostly presented their ideas 'on their own turn,' which we know to be a normal practice at school. The turn-based approach can be both useful (not letting anyone dominate the discussion) yet it can also stall the discussion and dampen or even break the creative process, as we saw happen a couple of times when the person whose turn it was did not have a new idea to present. For the child leader who has internalized these accustomed practices, it certainly is a challenge to understand this type of a problem and try to correct it. However, it seems that during a creative flow even the rules may be forgotten as, while drawing, the ideas were presented more at a random order. The very practical effect of the situated context is useful to note as it may really affect the session by setting certain kinds of expectations or assumptions for the participants on the 'correct behaviour,' affecting therefore both what the participants associate with their ideas as well as the interaction order between them (Bratteteig, 2004; Goffman, 1981, 1983; Le Dantec, 2010; MolinJuustila et al., 2015). In a school context, for example, children expect guidance from their teachers; they rely in general on adults for instructions, as showed also in our data. Alternatively, they may think that adults' ideas are somehow better than their own.

\subsection{Previous experiences, orientation, and facilitating events}

According to Vygotsky (2004) all creations are based on previous experiences. For professional designers, these experiences are related to both their design expertise as well as their subject expertise and all and every kind of experiences they have accumulated over time (cf. Bratteteig (2004)). For child designers, it is also useful to have both design and subject expertise, as pondered within the CI tradition (Yip, Clegg, et al., 2013).

To enhance our participants' basis of experiences related to subject expertise, we provided some practical examples (but not too many, cf. Sternberg (2006)) during the orientation phase, to explain the concept of tangible interaction. 
However, we intentionally did not provide any visible example that included the mock-up. Therefore, the younger children had no previous experience on that. That is a possible justification as to why there were multiple ideas that were not connected directly with the mock-up. The captain and the adult had some previous knowledge of the mock-up and the guidelines provided to the captain remarked explicitly that an important part of the process was to create ideas related to the mock-up. However, at some point the participants strayed away from ideas related to the mock-up, even though they started with those after hearing the instructions and seeing the example the captain used related to the mock-up. Only after seeing more examples provided by the adult and finally the clues provided by the researcher, the younger children started to connect their ideas with the mock-up again. Therefore, in our data the facilitating events by the captain, the adult, and the intervening researcher both provided structure for the session as well as provided experiences for the participants, to help their creative process.

The quiet captain did not have enough authority even though from the video we can see that she put strong efforts into guiding the group work, and the younger children clearly listen to her and also mostly try to do as she guides them. Unlike in Yip, Foss, et al.'s study (2013), our captain had no personal design interest (e.g., a prototype of her own) to start with. She was only facilitating the session according to her guidelines. We believe that this was useful, as the captain had no need to adhere to any specific idea but her role; instead, she was focused merely on the facilitation work. One reason for the captain's partly missing authority may be that she clearly did not consider herself a participant in the ideation process, thus her own behaviour did not strengthen her instructions. The role of a participant seems not to be that self-evident for a child leader having no personal design interest. When working with a similar kind of setting, we suggest considering which roles for a (child) leader are most fruitful regarding the session goals, and training the leader accordingly.

When the captain's beautiful, subtle gestures and guidance did not work, the younger children turned several times towards the university student, an adult, hoping for guidance and cues for what to do next. Even though the adult tried not to lead the children, just the fact that she was present seemed to positively facilitate the process somewhat. As the adult always asked correctly for facilitation from the captain, the children did not expect facilitation and guidance from her any more. However, at some critical points she helped to keep the flow of the session, either by simply asking for support from the captain or by providing an idea of her own after a halt in the session. Her elaboration of children's magical ideas may also have helped the creative process. Presence of the adult participants, as well as researcher interventions when she observed that the creative process was stalling, were clearly needed (cf. Guha et al. (2013) about adults providing structure for sessions). All in all, facilitators for a session are obviously needed, both when working with children and adults. It is fruitful to consider, however, what their role and background should 
be and how it affects the design process, such as through the facilitators' accumulated design and subject experience, as well as interaction order between the participants. With children, power relations between adults and children may have their own effect on the interaction order (cf., e.g., Druin (2002) and Guha et al. (2013) about power relations between children and adults in collaborative design sessions), and too much design or subject experience may also hamper the process (Sternberg, 2006).

\subsection{Timeline analysis}

Timeline analysis was a central method for us to make sense of what happened in this complex, collaborative creative process. In qualitative video analysis, the use of timeline charts to present relevant events is not an uncommon practice, and tools aimed at speeding up this process exist (Burr, 2006; Hagerdorn et al., 2008). In our case, we had a special interest in ideas that established relation links between the mock-up (Figure 3) and the participants' items. Hence, our problem space was divided in three dimensions: type of the event (a creative idea vs. a facilitating action), roles of the participants who generate the ideas, and physical elements (the mock-up, a participant's item, or some other artefact) that were part of the idea. The code chosen to represent significant events, separating clearly creative events and facilitator actions, helped us to identify which actions from the facilitators contributed most in the idea generation. Finally, separating in parallel lines the artefacts that were part of the idea (the items and the mock-up) served us to identify, for instance, how the use of pen and paper boosted significantly the number of ideas. We suggest researchers use a chart-based visualization to present the occurrence of relevant events in complex collaborative situations, for identification of both the events that are significant, as well as the role of the actors participating in such events (see Figure 7). Bratteteig et al. (2016) used a very similar type of timeline analysis for showing how design ideas develop over time.

\subsection{Lightweight method to use in school context}

Our background is in Scandinavian participatory design tradition, and a central goal of our research in general is to empower children by giving them an opportunity to take part in the technology design process, thus giving them wider understanding of their own possibilities to affect the technology they use and giving them a democratic possibility for learning new skills in the design process (see also Iivari and Kinnula 2016). Therefore, we look for methods that are usable in a school context. Regarding the lightweight method that we tried out, we felt that the basic setup worked despite the difficulties in the session, as the children were able to work in the school, in the middle of their normal school day, with their peers; i.e., the natural, genuine participation of children was possible (Iivari and Kinnula, 2016; Iivari et al., 2015). As our experience is that in a school context there is 
typically a rather limited amount of time to work with children and teachers are not able to do a lot of extra work, we therefore tried to limit the amount of work needed in addition to the actual design session: the $3^{\text {rd }}$ graders and the adult university students were trained only during the session orientation, we met the $5^{\text {th }}$ graders twice before the brainstorming session, and the teachers had hardly any extra work. Despite these restrictions, the children were still able to produce a large number of design ideas, and 12 of them we can utilize in our later research. By educating the children more we could have provided them more advanced knowledge on tangible interaction and maybe all the ideas would then have been related to the mock-up (cf. Yip, Clegg, et al., (2013), who propose educating children with both design and subject knowledge, to help the ideas to be better related to the specific subject during a design session). However, it would have required more time, and we aimed for a method that involves almost no training for the different actors.

Having an older child as a facilitator also worked well, despite the difficulties related to the creative process. Our captain was willing to continue in a captain's role later in the project. She could have easily refused to do that, had she wanted to. For the current paper, we did not make a careful analysis regarding our aims of empowering both the younger and older children by having a child leader in a group, but we argue that both the younger children as well as the captain gained new understanding related to technology design. They encountered a situation where an adult worked equally with them (quite rare even in the very low-hierarchy and relaxed country of Finland), and the captain specifically gained experience related to working as a leader of other children. We see this as one type of empowerment in itself (cf. Iversen and Smith (2012) about empowering children by Scandinavian participatory design). We were also able to see that, despite the troubles in the group's working, the younger children seemed to take the older child's role as a leader as a natural thing, especially as the child leader was supported by the adult in the group.

If older children are used as facilitators in a manner similar to this study, we suggest an open discussion with them related to what kind of challenging situations they may encounter in their facilitation work. Having a reflective discussion afterwards, as we did, would make it possible for the children to discuss possible frustrating situations and get support from both their peers as well as adults, who can put the issues in larger perspective and help in understanding why the situation was challenging. We believe that only listening to other $5^{\text {th }}$ grader's experiences and frustrations relieved some of the stress of our captain, even though she did not feel like discussing her own thoughts.

We also suggest discussing the training needs beforehand with the teachers and getting them to assist, and to possibly integrate some kind of leadership training as part of the normal school work (e.g., as part of basic, wide-ranging skills related to civic matters, working-life and entrepreneurship in the curriculum for primary education). Considering the genuine participation aspect (Iivari and Kinnula, 2016; 
Iivari et al., 2015) and empowerment of the child leaders, this would be even more important.

\section{Conclusion}

The central contribution of this paper is the preliminary theory-based understanding of how creativity is connected with different elements present in a creative act, as pictured in Figure 8. The basis for that is Vygotsky's (2004) creativity cycle. The timeline analysis method used in the study was essential for understanding what happened in our data. The creativity cycle together with the timeline method enabled us to see beneath the surface when examining a collaborative brainstorming session. Our results form a good basis for further methodological development of creative collaborative sessions, both with children and adults.

We see that the deliberate and conscious use of the creativity cycle in both planning the brainstorming sessions and, together with timeline analysis, for analysis purposes may have benefits for the research, particularly when the intention is to develop the methodology further. It can give possible explanations as to why a given method works or what shortcomings it may have, thus giving the researcher a much better understanding of the results and a possibility for adjusting the method by strengthening or weakening the effect of chosen elements (see Figure 8). It also provides some theoretically-based possible explanations for why some of the best practices already followed in the CCI field (especially in CI) work well. We suggest that our results are relevant also when working with all-adult groups.

We see an interesting possibility in creating mixed-age groups for brainstorming in contexts similar to our project. If we understood both the challenges and benefits of their use, that kind of groups might be suitable in regards of both creative work as well as empowering of children when the group is created rather ad hoc, without long-term collaboration or extensive training. As both the older child (the captain) and the participating adult (the university student in our data) were able to lead and give structure to the process with a minimal amount of training, we consider this worth looking into more deeply in the future. For the researchers short of resources, this kind of setup provides a possibility for a single researcher to handle; e.g., four parallel brainstorming sessions, as the researcher needs to facilitate the session only when the captain has some problems.

The obvious limitation to this study is its exploratory nature and, because of that, the small number of children and only one session with them. It is important to note, however, that related findings have been provided already in previous studies, as reported above; these have not been approached based on theory as has been done in the current study. The nature of the child leader and the other session participants may also have a strong influence on the results: participants with different personality traits might have created entirely different dynamics. We want 
to stress, however, that we don't feel that group dynamics are central in this paper, even though, of course, they affected the results that the group was able to produce.

The topic seemed also to be somewhat difficult for the children to grasp. However, the aim of the study was to consider the feasibility of the setting. The small amount of training the captain received can be seen as a limitation as well, but the school schedule did not allow us to meet her more often. Our intention was also to adapt to the constraints of the school, and we were trying to find the limits for as lightweight a method as possible. We suggest future studies to explore both how the theoretical understanding discussed in this paper serves methodology development, as well as the further development of the framework presented by us. Regarding the timeline analysis, we welcome other researchers to try it for visualizing complex interaction situations. More detailed understanding about the role and meaning of different material objects and their joint combinations, as well as how brainstorming is affected by a different mix of participants within mixedage group settings, would definitely also be interesting subjects for further research.

\section{Acknowledgements}

We would like to thank the children, teachers, and university students who took part in this study, particularly Anne-Marie Oikarinen.

\section{References}

Bratteteig, T. (2004). Making change. Dealing with relations between design and use. Ph.D. dissertation. University of Oslo, Oslo: Department of Informatics, Faculty of Mathematics and Natural Sciences.

Bratteteig, T.; O. K. Rolstad; and I. Wagner (2016). The life and death of design ideas. In A. De Angeli, L. Bannon, P. Marti and S. Bordin (eds.): COOP 2016. The 12th International Conference on the Design of Cooperative Systems, Trento, Italy, 23-27 May 2016. Springer International Publishing, pp. 259-275

Burr, B. (2006). VACA: A tool for Qualitative Video Analysis. In: CHI EA'06 Extended Abstracts on Human Factors in Computing Systems, Montréal, Québec, Canada, April 22-27, 2006. ACM, pp. 622-627

Chawla, L.; and H. Heft. (2002). Children's Competence and the Ecology of Communities: A Functional Approach to the Evaluation of Participation. Journal of Environmental Psychology, vol. 22, no. 1-2, 2002, pp. 201-216.

Decortis, F.; E. Rubegni; A. B. Tillon; and E. Ackermann (2013). Interactive technologies that enhance children's creativity. In: IDC '13. Proceedings of the 12th International Conference on Interaction Design and Children, New York, USA, June 24-27, 2013. ACM, pp. 596-599

Druin, A. (1999). Cooperative Inquiry: Developing New Technologies for Children with Children. In: CHI '99. Proceedings of the SIGCHI conference on Human Factors in Computing Systems. Pittsburgh, Pennsylvania, USA, May 15-20, 1999. ACM, pp. 592-599

Druin, A. (2002). The role of children in the design of new technology. Behaviour and information technology, vol. 21 , no. 1,2002 , pp. 1-25. 
Druin, A.; B. Bederson; A. Boltman; A. Miura; D. Knotts-Callahan; and M. Platt (1999). Children as our Technology Design Partners. In Allison Druin (ed.): The Design of Children's Technology. San Francisco: Kaufmann, pp. 51-72.

Fitzmaurice, G. W.; H. Ishii; and W. A. S. Buxton (1995). Bricks: Laying the foundations for graspable user interfaces. In: CHI '95. Proceedings of the SIGCHI Conference on Human Factors in Computing Systems, Denver, Colorado, USA, May 07-11, 1995. ACM, pp. 442449

Garzotto, F. (2008). Broadening children's involvement as design partners: From technology to "experience". In: IDC '08. Proceedings of the 7th international conference on Interaction design and children, Chicago, Illinois, June 11-13, 2008. ACM, pp. 186-193

Goffman, E. (1981). Forms of talk. Philadelphia: University of Pennsylvania Press.

Goffman, E. (1983). The interaction order. American Sociological Review, vol. 48, no. 1, 1983, pp. $1-17$.

Goodwin, C.; and M. H. Goodwin (1996). Seeing as a Situated Activity: Formulating Planes. In Y. Engeström and D. Middleton (eds.): Cognition and Communication at Work. Cambridge: Cambridge University Press, pp. 61-95.

Guha, M. L.; A. Druin; and J. A. Fails. (2013). Cooperative inquiry revisited: Reflections of the past and guidelines for the future of intergenerational co-design. International Journal of ChildComputer Interaction, vol. 1, no. 1, 2013, pp. 14-23.

Hagerdorn, J.; J. Hailpern; and K. G. Karahalios (2008). VCode and VData: Illustrative a new Framework for Supporting the Video Annotation Workflow. In: AVI '08. Proceedings of the working conference on Advanced Visual Interfaces, Napoli, Italy, May 28-30, 2008. ACM, pp. 317-321

Hanna, L.; K. Risden; and K. J. Alexander. (1997). Guidelines for usability testing with children. interactions, vol. 4, no. 5, 1997, pp. 9-14.

Hourcade, J. P. (2008). Interaction design and children. Foundations and Trends in HumanComputer Interaction, vol. 1, no. 4, 2008, pp. 277-392.

Iivari, N.; and M. Kinnula (2016). Inclusive or Inflexible - a Critical Analysis of the School Context in Supporting Children's Genuine Participation. In: NordiCHI '16. Proceedings of the 9th Nordic Conference on Human-Computer Interaction, Gothenburg, Sweden, October 2327, 2016. ACM, pp. 1-10

Iivari, N.; M. Kinnula; and L. Kuure. (2015). With best intentions - a Foucauldian examination on children's genuine participation in ICT design. Journal of Information Technology \& People, vol. 28, no. 2, 2015, pp. 246-280.

Ishii, H.; and B. Ullmer (1997). Tangible bits: Towards seamless interfaces between people, bits and atoms. In: CHI '97. Proceedings of the ACM SIGCHI Conference on Human factors in computing systems, Atlanta, Georgia, USA, March 22-27, 1997. ACM, pp. 234-241

Iversen, O. S.; and R. Smith (2012). Scandinavian participatory design: dialogic curation with teenagers. In: IDC '12. Proceedings of the 11th International Conference on Interaction Design and Children, Bremen, Germany, June 12-15, 2012. ACM, pp. 106-115

Jacucci, G.; and I. Wagner (2007). Performative roles of materiality for collective creativity. In: C\&C '07. Proceedings of the 6th ACM SIGCHI conference on Creativity \& Cognition, Washington DC, USA, June 13-15, 2007. ACM, pp. 73-82

Jewitt, Carey (ed.). (2009). The Routledge handbook of multimodal analysis. London, UK: Routledge.

Knoblauch, H.; A. Baer; E. Laurier; S. Petschke; and B. Schnettler. (2008). Visual Analysis. New Developments in the Interpretative Analysis of Video and Photography. Forum: Qualitative Sozialforschung/Forum: Qualitative Social Research, vol. 9, no. 3, 2008.

Knudtzon, K.; A. Druin; N. Kaplan; K. Summers; Y. Chisik; R. Kulkarni; S. Moulthrop; H. Weeks; and B. Bederson (2003). Starting an intergenerational Technology Design Team: A Case Study. In: IDC '03. Proceedings of the 2003 conference on Interaction design and children, Preston, UK, July 01-03, 2003. ACM, pp. 51-58

Kuure, L.; E. Halkola; N. Iivari; M. Kinnula; and T. Molin-Juustila (2010). Children Imitate! The issue of recycling in participatory design with children. In: PDC '10. Proceedings of the 
11th Biennial Participatory Design Conference, Sydney, Australia, November 29 December 03, 2010. ACM, pp. 131-140

Kuutti, K. (1994). Information systems, cooperative work and active subjects: the activitytheoretical perspective. Research papers. Series A 23. Oulu, Finland: Oulu University Printing Centre.

Kuutti, K.; G. Iacucci; and C. Iacucci (2002). Acting to Know: Improving Creativity in the Design of Mobile Services by Using Performances. In: C\&C'02. ACM SIGCHI conference on Creativity \& Cognition, Loughborough, UK, October 13-16, 2002. ACM, pp. 95-102

Large, A.; L. Bowler; J. Beheshti; and V. Nesset. (2007). Creating web portals with children as designers: Bonded design and the zone of proximal development. McGill Journal of Education, vol. 42, no. 1, 2007, pp. 61-82.

Le Dantec, C. A. (2010). Situating design as social creation and cultural cognition. CoDesign: International Journal of CoCreation in Design and the Arts, vol. 6, no. 4, 2010, pp. $207-$ 224.

Literat, I. (2013). "A Pencil for Your Thoughts": Participatory Drawing as a Visual Research Method with Children and Youth. International Journal of Qualitative Methods, vol. 12, no. 1, 2013, pp. 84-98.

Molin-Juustila, T.; M. Kinnula; N. Iivari; L. Kuure; and E. Halkola. (2015). Multiple voices in ICT design with children-a nexus analytical enquiry. Behaviour \& Information Technology, vol. 34 , no. 11,2015 , pp. 1079-1091.

Mondada, L. (2006). Video recording as the reflexive preservation and configuration of phenomenal features for analysis. In Hubert Knoblauch, Bernt Schnettler, Jürgen Raab and Hans-Georg Soeffner (eds.): Video Analysis. Bern: Lang, pp. 51-68.

Norooz, L.; and J. Froehlich (2013). Exploring Early Designs for Teaching Anatomy and Physiology to Children Using Wearable E-Textiles. In: IDC '13. Proceedings of the 12th International Conference on Interaction Design and Children, New York, New York, USA, June 24-27, 2013. ACM, pp. 577-580

Pardo, S.; F. Vetere; and S. Howard (2005). Broadening Stakeholder Involvement in UCD: Designers' Perspectives on Child-Centred Design. In: OZCHI'05. Proceedings of the 17th Australia conference on Computer-Human Interaction, Canberra, Australia, November 21-25, 2005. Computer-Human Interaction Special Interest Group (CHISIG) of Australia, pp. 1-9

Plucker, J. A.; R. A. Beghetto; and G. T. Dow. (2004). Why isn't creativity more important to educational psychologists? Potentials, pitfalls, and future directions in creativity research. Educational psychologist, vol. 39, no. 2, 2004, pp. 83-96.

Rode, J.; M. Stringer; E. F. Toye; A. R. Simpson; and A. F. Blackwell (2003). Curriculum-focused design. In: IDC '03. Proceedings of the 2003 conference on Interaction design and children Preston, England, July 01-03, 2003. ACM, pp. 119-126

Scaife, M.; and Y. Rogers (1999). Kids as Informants: Telling us what we didn't know or confirming what we knew already. In A. Druin (ed.): The Design of Children's Technology. San Francisco: Kaufmann, pp. 27-50.

Schön, D. (1983). The reflective practitioner. How professionals think in action. New York: Basic Books.

Schön, D. A. (1992). Designing as reflective conversation with the materials of a design situation. Knowledge-based systems, vol. 5, no. 1, 1992, pp. 3-14.

Sellen, A.; and R. Harper. (2002). The Myth of the Paperless Offices. MA: MIT Press.

Shaer, O.; and E. Hornecker. (2010). Tangible user interfaces: past, present, and future directions. Foundations and Trends in Human-Computer Interaction, vol. 3, no. 1-2, 2010, pp. 1-137.

Sternberg, R. J. (2006). The Nature of Creativity. Creativity Research Journal, vol. 18, no. 1, 2006, pp. 87-98.

Thang, B.; W. Sluis-Thiescheffer; T. Bekker; B. Eggen; A. Vermeeren; and H. d. Ridder (2008). Comparing the creativity of children's design solutions based on expert assessment. In: IDC '08. Proceedings of the 7th international conference on Interaction design and children, Chicago, Illinois, USA, June 11-13, 2008. ACM, pp. 266-273 
Vyas, D.; D. Heylen; A. Nijholt; and G. Van Der Veer (2009). Collaborative practices that support creativity in design. In I. Wagner, H. Tellioğlu, E. Balka, C. Simone, and L. Ciolfi (eds.) ECSCW 2009. Proceedings of the European Conference on Computer-Supported Cooperative Work. Springer, pp. 151-170

Vygotsky, L. S. (2004). Imagination and Creativity in Childhood. Journal of Russian and East European Psychology, vol. 42, no. 1, 2004, pp. 7-97.

Walsh, G.; E. Foss; J. Yip; and A. Druin (2013). FACIT PD: A Framework for Analysis and Creation of Intergenerational Techniques for Participatory Design. In: CHI '13. Proceedings of the SIGCHI Conference on Human Factors in Computing Systems, Paris, France, April 27 - May 02, 2013. ACM, pp. 2893-2902

Wang, G. G.; T. Ye; L. Enmao; W. Yunfan; Y. Cheng; and Y. Fangtian (2015). Constructive Play: Designing for Role Play Stories with Interactive Play Objects. In: TEI '15. Proceedings of the 9th International Conference on Tangible, Embedded, and Embodied Interaction, Stanford, California, USA, January 15-19, 2015. ACM, pp. 575-580

Warr, A.; and E. O'Neill (2005). Understanding design as a social creative process. In: $C \& C^{\prime} 05$. Proceedings of the 5th ACM SIGCHI conference on Creativity \& Cognition, London, United Kingdom, April 12-15, 2005 ACM, pp. 118-127

Yarosh, S.; I. Radu; S. Hunter; and E. Rosenbaum (2011). Examining values: an analysis of nine years of IDC research. In: IDC '11. Proceedings of the 10th International Conference on Interaction Design and Children, Ann Arbor, Michigan, USA, June 20-23, 2011. ACM, pp. 136-144

Yip, J.; T. Clegg; E. Bonsignore; H. Gelderblom; E. Rhodes; and A. Druin (2013). Brownies or Bags-of-Stuff? Domain Experts in Cooperative Inquiry with Children. In: IDC '13. Proceedings of the 12th International Conference on Interaction Design and Children, New York, New York, USA, June 24-27, 2013. ACM, pp. 201-210

Yip, J.; E. Foss; E. Bonsignore; M. L. Guha; L. Norooz; E. Rhodes; B. McNally; P. Papadatos; E. Golub; and A. Druin (2013). Children Initiating and Leading Cooperative Inquiry Sessions. In: IDC '13. Proceedings of the 12th International Conference on Interaction Design and Children, New York, New York, USA, June 24-27, 2013. ACM, pp. 293-296 